\title{
Koroner arter hastalığı olanlarda medikal tedavi ve yaşam tarzı değişikliklerine uyumun değerlendirilmesi
}

\author{
Evaluation of adherence to medical treatment and lifestyle changes at coronary \\ artery disease
}

İpek Büber, Cihan Illyas Sevgican

Gönderilme tarihi:04.01.2022

Kabul tarihi:11.01.2022

\section{Öz}

Amaç: Koroner arter hastalığı $(\mathrm{KAH})$ için sekonder korumada medikal tedavi (MT) yaşam tarzı değişikliklerine (YTD) uyum hastalığa bağlı mortalite ve morbiditeyi azaltmaktadır. Bu çalışmada KAH hastalarında MT ve YTD'ye uyumu etkileyen parametrelerin araştırılması amaçlanmıştır.

Gereç ve yöntem: En az bir yı önce farklı sebeplerle koroner anjiografi yapılarak KAH tanısı almış ardışık 396 hastaya uyumu değerlendirmek üzere standardize edilmiş anket uygulanmıştır.

Bulgular: Hastaların \%20,9'u (n=83) YTD'ye uyumsuz, \%42,4'ü $(n=168)$ orta derecede uyumlu, \%36,6'sı $(n=145)$ uyumlu saptanmıştır. \%81,1'i ise $(n=321)$ MT'ye tam uyumlu saptanmıştır. Erkek cinsiyet (RA:1,966, $p=0,023$ ), daha genç yaş (yaş, RA:0,958, $p=0,002$ ), KABG yapılması YTD'ye uyumu arttırırken (RA:2,635, $p=0,015)$, ST elevasyonsuz miyokart enfarktüsü/unstabil angina pektoris nedeniyle koroner anjiografi yapılmış olması (RA:0,344, $p=0,001)$ ve ST elevasyonlu miyokart enfarktüsü/ölümcül aritmi nedeniyle koroner anjiografi yapılmış olması (RA:0,472 $p=0,014$ ) YTD'ye tam uyumluluk üzerine negatif etkilidir. Hipertansiyon varlığı (RA:5,779 p<0,001), ST elevasyonlu miyokart enfarktüsü/ölümcül aritmi (RA:3,736, $p=0,029)$ varlığı MT'ye uyumu arttırırken, perkütan koroner girişim uygulanması (RA:0,132, $p=0,002$ ) MT'ye uyumu azaltmaktadır.

Sonuç: Ülkemizde KAH hastalarında MT'ye uyum YTD'ye uyumdan daha yüksektir. Genç yaş erkek hastalar YTD'ye daha fazla uyum sağlarken bu etki MT'de saptanmamıştır. Gelir düzeyinin orta ve yüksek olması YTD'ne uyumu pozitif yönde etkilerken MT üzerine net etki saptanmamıştır. Girişim yapılma nedeni MT ve YTD'ye uyumu etkilemektedir.

Anahtar kelimeler: Yaşam tarzı değişikliklerine uyum, medikal tedaviye uyum, koroner arter hastalığı.

Büber İ, Sevgican Cl. Koroner arter hastalığı olanlarda medikal tedavi ve yaşam tarzı değişikliklerine uyumun değerlendirilmesi. Pam Tıp Derg 2022;15:239-250.

\begin{abstract}
Purpose: Adherence to medical treatment (MT) and lifestyle changes (LC) in secondary prevention for coronary artery disease (CAD) reduces disease-related mortality and morbidity. In this study, we aimed to investigate the parameters affecting compliance with MT and LC in patients with CAD.

Material and method: A standardized questionnaire was applied to 396 consecutive patients who were diagnosed with CAD by performing coronary angiography for different reasons at least one year ago, to evaluate adherence.

Results: $20.9 \%$ of the patients ( $n=83)$ were found to be non-adherent to LC, $42.4 \%(n=168)$ were intermediateadherent, and $36.6 \%(n=145)$ were adherent. $81.1 \%(n=321)$ of the patients were found to be fully adherent to MT. Male gender (Cl:1.966, $p=0.023$ ), younger age (age, RA:0.958, $p=0.002$ ), performing coronary artery bypass grafting $(\mathrm{Cl}: 2.635, p=0.015)$ increased adherence to LC, conversely non-ST elevation myocardial infarction/unstable angina pectoris $(\mathrm{Cl}: 0.344, p=0.001)$ and ST-elevation myocardial infarction/fatal arrhythmia $(\mathrm{Cl}: 0.472 p=0.014)$ decreased adherence. Presence of hypertension $(\mathrm{Cl}: 5,779, p<0.001)$, ST-elevation myocardial infarction/fatal arrhythmia $(\mathrm{Cl}: 3.736, p=0.029)$ increased adherence to MT but percutaneous coronary intervention $(\mathrm{Cl}: 0.132, p=0.002)$ decreased adherence to MT.

Conclusion: Adherence to MT is higher than LC in patients with CAD in our study population. Younger male patients were more adherent to LC but this effect was not observedadherence to LC. The medium and high-income level positively affected the adherence to LC but not MT. The reason for the intervention affects adherence to both MT and LC.
\end{abstract}

Key words: Adherence to medically treatment, adherence to lifestyle changes, coronary artery disease.

Buber I, Sevgican Cl. Evaluation of adherence to medical treatment and lifestyle changes at coronary artery disease. Pam Med J 2022;15:239-250.

İpek Büber, Dr. Öğr. Üye. Pamukkale Üniversitesi Tıp Fakültesi, Kardiyoloji Anabilim Dalı, Denizli, Türkiye, e-posta: isemerci@pau.edu.tr (https://orcid.org/0000-0003-2457-313X) (Sorumlu Yazar)

Cihan İlyas Sevgican, Arş. Gör. Dr. Pamukkale Üniversitesi Tıp Fakültesi, Kardiyoloji Anabilim Dalı, Denizli, Türkiye, e-posta: c7sevgican@ gmail.com (https://orcid.org/0000-0002-8750-7335) 


\section{Giriş}

Uyum, Dünya Sağlık Örgütünün (DSÖ) tanımına göre bir bireyin ilaç kullanmak, beslenme ve yaşam tarzı değişikliklerine (YTD) bağlılık derecesi olarak tanımlanır ve kronik hastalık yönetiminde hayati bir rol oynar (Dünya Sağlık Örgütü, 2003). DSÖ tarafından geliştirilen çerçeveye göre, tedavi uyumunu etkileyen beş faktör mevcuttur; 1) sosyal ve ekonomik faktörler, 2) sağlık sistemi ve sistemle ilgili faktörler, 3) durumla ilgili faktörler, 4) tedaviyle ilgili faktörler, 5) hasta ile ilgili faktörler.

Koroner arter hastalığı (KAH) dünya çapında yüksek mortalite ve morbiditeye sahiptir bu nedenle ikincil korumada YTD ve medikal tedavi (MT) önerilerine uyum önemlidir [1]. Araştırmalar, zayıf uyumun hastalığa özgü hastaneye yatışlarını, komplikasyonları, tüm nedenlere bağlı ölümleri ve sağlık harcamalarını arttırdığını göstermiştir [2, 3] ve $\mathrm{KAH}$ hastalarında uyum tanı sonrası zamanla azalan bir ivme göstermektedir. Bir çalışma, akut koroner sendromlu (AKS) hastaların neredeyse üçte birinin taburcu olduktan sonraki 3 ay içinde MT'ye uyumu sonlandırdığını göstermiştir [4]. Başka bir çalışmada KAH hastalarında MT'ye uyumsuzluğun mortaliteyi \%50-80 kardiyak nedenli hastaneye yatışları \%10-40 artırdığı gösterilmiştir [5].

Ülkemizde KAH tanılı hastalarda MT ve YTD uyumun değerlendirilmesi ile ilgili çalışmalar sınırlı kalmaktadır. Bu çalışmada farklı klinik tablolar ile KAH tanısı almış hastaların MT ve YTD'ye uyumunu ve bu konuda etkili olabilecek faktörleri araştırmayı amaçladık.

\section{Gereç ve yöntem}

$\mathrm{Bu}$ çalışma Pamukkale Üniversitesi Tıp Fakültesi, Girişimsel Olmayan KlinikAraştırmalar Etik Kurulu tarafından onaylanmıştır. Çalışma Helsinki Bildirgesine göre yürütülmüştür.

Hastalardan anket soruları sorulmadan önce aydınlatıımış onam alınmıştır.

\section{Hasta seçimi ve anketin uygulanması}

Bu çalışma Ocak 2020 ile Haziran 2020 Pamukkale Üniversitesi Kardiyoloji polikliniğinde yapılan kesitsel bir çalışmadır. Değerlendirmeden en az bir yıl önce koroner anjiyografi (KAG) yapılmış, en az bir koroner arterde \%50'den fazla darlık olan ve bu nedenle MT alan ve/veya perkütan koroner girişim ya da koroner arter bypass greftleme (KABG) yapılan tüm hastalara anket uygulandı. Toplamda 396 hasta çalışmaya dahil edildi.

Dışlama kriterleri hastanın bilişsel olarak kendi öz bakımını üstlenememesi, son dönem karaciğer ve ileri dönem böbrek yetmezliği (glomerüler filtrasyon hızı $<30 \mathrm{~mL} /$ dakika/1,73 $\mathrm{m}^{2}$ ), malignensi öyküsü veya aktif malignite nedeniyle tedavi alıyor olması, iletişim zorluğu nedeniyle soruların cevaplanamaması olarak belirlendi. Ek hastalık bölümünde kronik böbrek yetmezliği terimi glomeruler filtrasyon hızı 30 ile $60\left(30 \mathrm{~mL} /\right.$ dakika/1,73 $\left.\mathrm{m}^{2}\right)$ arasında olan hastalar için kullanıldı.

Kriterlere uyan tüm hastalara standardizasyon sağlanması için MT ve YTD'ye uyumu sorgulayan anket uygulandı (Anket 1).

\section{Klinik verilerin toplanması}

Hasta bilgileri hastane elektronik sisteminden ve hastadan alınan anamnezle toplandı. Anket anındaki boy ve kilo bilgileri kaydedildi. Beden kitle indeksi kilo $(\mathrm{kg}) /$ boy $\left(\mathrm{m}^{2}\right)$ formülü kullanılarak hesaplandı. Hipertansiyon (HT) varlığı, $>140 \mathrm{mmHg}$ sistolik ve/veya diyastolik basınç $>90 \mathrm{mmHg}$ basınç veya bireyin antihipertansif ilaç kullanması olarak tanımlandı. Diyabet (DM) varlığı (açlık glikoz seviyesi $>126 \mathrm{mg} / \mathrm{dL}$ veya hastanın anti-diyabetik ilaç alması olarak tanımlandı. Güncel hiperlipidemi klavuzlarına göre [6] hedef LDL değerinin üzerinde olan ve günlük antihiperlipidemik ilaç kullanmak zorunda olan hastalar hiperlipidemi (HL) olarak kaydedildi. DM mevcut veya olmaksızın statin kullanmak zorunda olan hastalar hiperlipidemi olarak tanımlandı. Günlük inhaler bronkodilatator ve/veya kortikosteroid kullanım intiyacı olan, göğüs hastalıkları kliniği tarafından kronik obstuktif akciğer hastalığı $(\mathrm{KOAH})$ tanısı ile takip edilen hastalarda $\mathrm{KOAH}$ varlığı kaydedildi. Kronik böbrek yetmezliği (KBY) terimi glomeruler filtrasyon hızı 30 ile 60 (30 $\mathrm{mL} /$ dakika/1,73 $\mathrm{m}^{2}$ ) arasında olan hastalar için kullanıldı. Hipotiroidi veya hipertiroidi nedeniyle endokrinoloji kliğinden takipli olan ve aktif ilaç kullanan hastalar ek hastalık bölümünde tiroid bozukluğu olarak kaydedildi. Ek olarak yukarıda belirtilmeyen hastalıklardan tanı almış ve günlük ilaç kullanım olan hastalar ek hastalık bölümünde diğer olarak kaydedildi. Aktif sigara içen hastalar veya sigara bırakma kararı üzerinden 6 ayı doldurmamış hastalar sigara içicisi olarak kaydedildi. 


\section{ANKET}

Hasta Adı Soyadı:

Dosya Numarası:

Boy / Kilo:

$\mathrm{Cm} /$

1. Yaş:

2. Cinsiyet:

3. Medeni Durum:
0.Bekar
1.Evli
2.Dul

4. Eğitim Durumu:

$\begin{array}{ll}\text { 1.İlkokul } & \text { 2.Ortaokul } \\ \text { 3.Lise } & \text { 4.Üniversite } \\ \text { 5.Yüksek Lisans } & \end{array}$

5. Sosyal Güvenceniz Nedir?
1.SSK
2.Bağkur
3.Emekli Sandığı
4.Yurtdışı
5.Diğer
6. Yok

6. Gelir Düzeyi
1. $0-2.000$
2. $2.000-4.000$
3. 4.000 Ve Üzeri

7. HT: 0 Yok

8. DM: 0 Yok 1 Var 1a.Insülin Bağımlı DM

1b.Oad

9. HL: 0 Yok 1 Var

10. Kky: 0 Yok 1 Var

11. Ek Hastalık:
0.Yok 1.Koah 2.Kby
3.Guatr 4.Diğer

12. Koroner Müdahale Yapıldı Mı?
0.Yok
1.Ptca veya Stent
2.Cabg

13. Koroner Girişim Nedeni?
1.STEMI
2.NSTEMI
3.USAP
4.Stabil Angina / Efor ve Mps Pozitifliği
5.Ölümcül Aritmi

14. Koroner Girişim Öncesi Sigara Kullanım Durumu:
0.Yok 1.Var
2.Ex Smoker
(EX: İşlemden En Az 1 Yıl Önce Bırakmış)

15. Girişim Sonrası Sigarayı Bıraktı Mı?
0 Hayır
1 Evet

16. Kalp Rahatsızı̆̆ı Gelişeceğini Bilseydiniz Sigarayı Daha Önceden Bırakır Mıydınız?
0 Hayır
1 Evet
2 Bilmiyorum

17. Sigaraya Tekrar Başladı Mı?
0 Hayır
1 Evet

18. Koroner Girişim Sonrası Medikal Tedaviye Düzenli Devam Etti Mi?

(cevabınız hayır ise 19-20. soruları cevaplayınız)
0 Hayır
1 Evet

19. Girişimden Ne Kadar Süre Sonra Medikal Tedaviyi Bıraktı? ay

20. Bırakma Nedeni Nedir?

(birden fazla işaretleyebilirsiniz)

1. Medikal Tedavi Hakkında Yeterli Bilgi Verilmemesi

2. Çok Fazla İlaç Kullanması

3. Kendini İyi Hissetmesi Ve İlaca Gerek Olmadığını Düşünmesi

4. Sağlık Hizmetlerine Yetersiz Ulaşım

5. Çevre Desteğinin Olmaması

6. Sosyal Medya Ve Tv Den Gereksiz Olduğunu İşitmesi

7. Gün İçinde Çalışıyor OImasından Dolayı Yanında Taşımaması

8. Diğer 
21. Koroner Girişim Sonrası Diyet Ve Fiziksel Aktivite Konusunda Hekim Tarafından Önerilerde Bulunuldu Mu? 0 Hayır 1 Evet

22. Önerilen Diyetinizi Uyguladınız Mı?
0 Hayır 1 Evet
1a. Diyetisyen eşliğinde uyguladım
1b. Dyt desteği almadım

23. Diyetinizde;

\begin{tabular}{|l|l|l|l|}
\hline & Yaptım & Kısmen yaptım & Yapmadım \\
\hline Tuz kısıtlaması & & & \\
\hline Hayvansal yağ tüketimini azaltma & & & \\
\hline Sebze tüketimini artırma & & & \\
\hline
\end{tabular}

24. Egzersiz Yapıyor Musunuz?

\begin{tabular}{|l|l|l|l|}
\hline Koroner Girişim & Düzenli Yapıyorum & Ara ara Yapıyorum & Hiç \\
\hline ÖNCESi & & & \\
\hline SONRASI & & & \\
\hline
\end{tabular}

25. Koroner Girişim Sonrası Egzersiz Yapmaya Başladı Mı?
0 Hayır
1 Evet

26. STENT İşleminden Sonra Size Kan Sulandırıcı İlaçları Kullanacağınız Süre İle İlgili Bilgi Verildi Mi?

0 Hayır 1 Evet (Süre: .........)

*Tüm sorularda gerekirse birden fazla işaretleyebilirsiniz

\section{Medikal tedaviye uyum sınıflarının belirlenmesi}

18. soruya (Koroner Girişim Sonrası MT'ye Düzenli Devam Etti Mi?) Evet yanıtını verenler MT uyum konusunda uyumlu, hayır yanıtını verenler ise MT'ye uyum konusunda uyumsuz grubuna dahil edildi. Girişimden sonra sadece belirli bir süre MT'ye devam eden hastalar 19. (Girişimden Ne Kadar Süre Sonra MT'yi Bıraktı? sorusuna 1 yıldan kısa süre ile cevap veren hastalar) ise MT'ye uyum konusunda orta derecede uyumlu grubuna dahil edildi.

\section{Yaşam tarzı değişikliklerine uyum sınıflarının belirlenmesi}

23. (Tuz kısıtlaması, Hayvansal yağ tüketimini azaltma, sebze tüketimini arttırma konularında; Yaptım, Kısmen yaptım ve Yapmadım) soruları ile 25. (Koroner Girişim Sonrası Egzersiz Yapmaya Başladı Mı?) sorusuna verilen cevaplar doğrultusunda YTD'ye uyum grupları belirlendi. 23. soruda hayatında gerekli tüm değişiklikleri yapan hastalar ile 25. soruda egzersize başlayan hastalar YTD'ye uyum konusunda uyumlu gruba, 23. soruda gerekli hiçbir değişikliği yapmayan hastalar ile 25. soruda egzersize başlamayan hastalar YTD'ye uyumsuz gruba, bu iki kriteri de tam karşılamayan kalan diğer hastalar orta derecede uyumlu gruba dahil edildi.

\section{İstatistiksel analiz}

Hastalara ait verilerde sürekli değişkenler ağırlıklı ortalama \pm standart sapma olarak, kategorik değişkenler ise $n,(\%)$ olarak özetlendi. Verilerin normallik dağılımları KolmogorovSmirnov ve Shapiro-Wilk testleri kullanılarak kontrol edildi. Kategorik değişkenlerin gruplar arasında karşılaştırılması için ki-kare testi, sürekli değişkenlerin ikiden fazla gruplar arasında karşılaştırılması için tek yönlü ANOVA testi kullanıldı. İki grubun sürekli değişkenlerinin karşılaştırıması gereken durumda bağımsız değişkenler için $T$ testi ve Mann-Whitney-U testleri kullanıldı. $P<0,05$ istatistiksel açıdan anlamlı olarak belirlendi.

Yapılan lojistik regresyon analizlerinde gruplar içerisindeki denek sayısının düşük olması nedeniyle gelir düzeyi değişkenleri, düşük gelir düzeyi bir grup olarak belirlenirken orta ve yüksek gelir düzeyi gruplarının toplamı diğer grup olarak belirlenmiş ve lojistik regresyon analizine bu şekilde dahil edilmiştir. Yine benzer şekilde koroner girişim nedeni değişkenleri içerisinde stabil angina pektoris ve miyokard perfuzyon sintigrafisinde iskemi saptandığı için koroner anjiyografi yapılan gruplar birleştirilmiş ve referans grup oluşturulmuştur. Aynı başlıkta ST elevasyonsuz miyokard enfarktüsü (NSTEMi) ve unstabil angina pektoris (USAP) gruplarına dahil olan hastalar birleştirilerek 
bir grup, ST elevasyonu miyokard enfarktüsü (STEMI) ve ölümcül aritmi ile başvuran gruplar birleştirilerek diğer bir grup oluşturulmuştur. Lojistik regresyon analizlerine koroner girişim nedeni değişkeni bu üç grup ile dahil edilmiştir.

Lojistik regresyon analizlerinde, mevcut gruplarda denek sayısının göreceli azlığı nedeniyle yaşam tarzı değişikliklerine uyumsuz ve YTD'ye orta derecede uyumlu grup birleştirilerek YTD'ye tam uyumlu olmayan grup adı verildi. YTD'ye uyumlu grup ise YTD'ye tam uyumlu grup olarak analize alındı. Lojistik regresyon analizi YTD'ye tam uyumlu olmayan grup referans alınarak YTD'ye tam uyumluluk üzerine etkili faktörleri araştırmak amaçlı yapıldı. MT'ye uyumluluk grupları için de aynı yöntem uygulanarak lojistik regresyon analizi yapıldı. Lojistik regresyon analizleri, MT'ye uyumu ve YTD'ye uyumu etkileyebilecek klinik ve sosyal faktörler göz önüne alınarak yapıldı.

\section{Bulgular}

Toplam 396 hasta [276 (\%69,7) erkek, 120 $(\% 30,3)$ kadın] çalışmaya alınmıştır. Tablo 1 'de hastaların demografik ve klinik özellikleri genel olarak gösterilmektedir. Koroner girişim öncesi sigara kullanımı toplam çalışma popülasyonu içerisinde $147(\% 37,1)$ hastada mevcuttu. Bu hastaların 87'si (147 hasta içerisindeki oran $\% 59,2)$ girişim sonrası sigarayı bıraktıklarını ifade ettiler. Bununla birlikte, 16. "Kalp Rahatsızlığı Gelişeceğini Bilseydiniz Sigarayı Daha Önce Bırakır Mıydınız" sorusuna hastaların 138'i (soruya cevap verenler $(n=189)$ içerisindeki oran $\% 73,0$ ) evet cevabı verdi. Sadece 12 katılımcı sigara içmeye tekrar başladıklarını belirttiler.111 $(\% 28,03)$ hasta günde 4 tablet ilaç almaktadır ve koroner girişimden sonra MT bırakma nedeni olarak en sık sebep çok fazla ilaç kullanımı $\mathrm{n}=48(\% 59,3)$ olarak belirtildi (Soru 20. Medikal Tedaviyi Bırakma Nedeni Nedir?)

Hekimler tarafından 273 hastaya $(\% 68,9)$ koroner anjiyografi sonrasında diyet ve fiziksel aktivite önerisinde bulunulduğu saptandı (Soru 21. Koroner Girişim Sonrası diyet ve fiziksel aktivite konusunda hekim tarafından önerilerde bulunuldu mu?). 26. STENT Işleminden Sonra Size Kan Sulandırıcı Illaçları Kullanacağınız Süre Ille IIlgili Bilgi Verildi Mi? sorusuna 153 katılımcıdan sadece 81 'i $(\% 52,9)$ "Evet" cevabını verdi.
Tablo 2'de hasta popülasyonunun yaşam tarzı değişikliklerine ve medikal tedaviye uyum konusundaki verileri hasta gruplarına ayrılarak özetlenmiştir. Hastaların \%20,9'u (n=83) YTD'ye uyumsuz, \%42,4'ü $(n=168)$ orta derecede uyumlu, \%36,6'sı ( $n=145$ ) uyumlu saptanmıştır. Yaş, cinsiyet, eğitim durumu, sosyal güvence, hiperlipidemi (HL), ek hastalık bulunması ile YTD'ye uyum grupları arasında istatiksel olarak ilişki varken, MT'ye uyum grupları arasında istatistiksel ilişki saptanmamıştır $(p=0,029$, $p=0,948), \quad(p=0,001, \quad p=0,054), \quad(p=<0,001$, $p=0,202), \quad(p=<0,001, \quad p=0,55), \quad(p=0,04$, $p=0,061), \quad(p=<0,001, \quad p=0,056) . \quad$ Sirasıyla; YTD'ye uyum, MT'ye uyum; yaş, cinsiyet, eğitim durumu, sosyal güvence, $\mathrm{HL}$, ek hastalık varlığı]. Hastaların \%81,1'i (n=321) MT'ye tam uyumlu saptanmıştır. DM varlığı, gelir düzeyi, koroner müdahale kararı alınması ve girişim yapılma nedeni grupları ile hem YTD'ye uyum hem de MT'ye uyum arasında istatistiksel ilişki saptanmıştır [sırasıyla; YTD'ye uyum, MT'ye uyum $(p=0,012, p=0,004)(p=<0,001, p=0,001)$, $(p=0,001, \quad p=0,002), \quad(p=0,004, \quad p=<0,001)]$. Benzer şekilde medeni durum ile MT'ye uyumluluk arasında istatistiksel ilişki mevcuttur $(p=0,048)$.

\section{Yaşam tarzı değişikliklerine tam uyumluluğun değerlendirilmesi}

YTD’yetamuyumluluküzerineetkiliolabilecek faktörler ile ilgili univariate ve multivariate lojistik regresyon analizi Tablo 3'de gösterilmiştir. Erkek cinsiyet (RA:2,535, $p<0,001)$ daha genç olmak (yaş, RA: 0,976, $p=0,032$ ), orta ve yüksek gelir düzeyi (RA:2,121, $p<0,001)$, eğitim durumunun lise (RA:2,876, $p<0,001)$, üniversite (RA: 3,013, $p=0,001)$ yüksek lisans olması (RA:5,273, $p=0,021)$, hastanın insülin tedavi rejimi alması (RA:2,800, $p=0,003)$, HL (RA:1,667, $p=0,017)$, KABG yapılmış olması (RA:2,400, $p=0,009)$, kronik böbrek yetmezliği olması (RA:9,483, $p<0,001)$ YTD'ye tam uyumluluk üzerinde etkilidir. NSTEMI/USAP tanısı ile girişim yapılanlar ile stabil angına ve miyokard perfuzyon sintigrafisi pozitifliği nedeniyle KAG yapılanlar ile kıyaslandığında YTD'ye uyumu azaltmaktadır (RA:0,425, $p=0,002$ ). Multivariate lojistik regresyon analizine göre erkek cinsiyet (RA:1,966, $p=0,023$ ), daha genç yaş (yaş, $\mathrm{RA}: 0,958, p=0,002$ ), KABG yapılması (herhangi bir tedavi uygulanmamış olması kategorisine göre) uyumu arttırırken (RA:2,635, $p=0,015)$, 
Tablo 1. Hastaların demografik ve klinik özellikleri

\begin{tabular}{|c|c|c|c|}
\hline & Hastalar $(n=396)$ & & Hastalar $(n=396)$ \\
\hline Cinsiyet, erkek & $276(\% 69,7)$ & Kilo, kg & $78,37 \pm 12,75$ \\
\hline HT & $231(\% 58,33)$ & Yaş, yıl & $63,77 \pm 9,17$ \\
\hline DM & $177(\% 44,7)$ & Ek hastalık & \\
\hline $\mathrm{HL}$ & $216(\% 54,55)$ & $\mathrm{KOAH}$ & $39(\% 9,85)$ \\
\hline KKY & $72(\% 18,18)$ & KBY & $18(\% 4,55)$ \\
\hline Sigara kullanımı & $147(\% 37,1)$ & Tiroid bozukluğu & $18(\% 4,55)$ \\
\hline Medeni durum & & Diğer & $69(\% 17,42)$ \\
\hline Bekar & $9(\% 2,27)$ & Alınan müdahale kararı & \\
\hline Evli & $333(\% 84,09)$ & PKG & $234(\% 59,09)$ \\
\hline Dul & $54(\% 13,64)$ & KABG & $87(\% 21,97)$ \\
\hline Eğitim durumu & & Yok & $75(\% 18,93)$ \\
\hline İlkokul & $240(\% 60,61)$ & Girişim yapılma nedeni & \\
\hline Ortaokul & $33(\% 8,33)$ & USAP & $51(\% 13,6)$ \\
\hline Lise & $69(\% 17,42)$ & NSTEMI & $72(\% 19,2)$ \\
\hline Üniversite & $45(\% 11,36)$ & STEMI & $117(\% 31,2)$ \\
\hline Yüksek lisans & $9(\% 2,27)$ & $\begin{array}{l}\text { Stabil angina- MPS } \\
\text { pozitifliği }\end{array}$ & $123(\% 32,8)$ \\
\hline Sosyal güvence & & Ölümcül aritmi & $12(\% 3,2)$ \\
\hline SSK & $216(\% 54,55)$ & İlaç tedavisi & \\
\hline Bağkur & $66(\% 16,67)$ & ASA & $273(\% 68,94)$ \\
\hline Emekli sandigi & $102(\% 25,76)$ & Klopidogrel & $96(\% 24,24)$ \\
\hline Yurtdisi & $0(\% 0)$ & p2y12 inhibitörü & $24(\% 6,06)$ \\
\hline Diğer & $9(\% 2,27)$ & Beta bloker & $303(\% 76,52)$ \\
\hline Gelir düzeyi & & ACE inhibitörü/ARB & $207(\% 52,27)$ \\
\hline $0-2000$ も & $210(\% 53,44)$ & MRA & $33(\% 8,33)$ \\
\hline 2000-4000も & $171(\% 43,51)$ & Digoksin & $9(\% 2,27)$ \\
\hline 4000 も ve üzeri & $12(\% 3,05)$ & Antianginal diğer & $60(\% 15,15)$ \\
\hline İlaç kullanım sayıları & & Nitrat & $54(\% 13,64)$ \\
\hline Günlük 0 tablet & $30(\% 7,58)$ & Statin & $225(\% 56,82)$ \\
\hline Günlük 1 tablet & $24(\% 6,06)$ & KKB & $75(\% 18,94)$ \\
\hline Günlük 2 tablet & $39(\% 9,85)$ & Diuretik & $36(\% 9,09)$ \\
\hline Günlük 3 tablet & $99(\% 25)$ & Coumadin & $18(\% 4,55)$ \\
\hline Günlük 4 tablet & $111(\% 28,03)$ & YOAK & $21(\% 5,3)$ \\
\hline Günlük 5 ve üzeri tablet & $30(\% 7,58)$ & Ezetimib & $6(\% 1,52)$ \\
\hline
\end{tabular}

HT: hipertansiyon, DM: diabetes mellitus, HL: hiperlipidemi, KKY: konjestif kalp yetmezliği, KOAH: kronik obstruktif akciğer hastalığı KBY; kronik böbrek yetmezliği, PKG; perkütan koroner girişim, KABG; koroner arter bypass greftleme, USAP; unstabil angina pektoris NSTEMI; non ST elevasyonlu miyokard enfarktüsü, STEMI; ST segment elevasyonlu miyokard enfarktüsü

MPS; miyoakrd perfüzyon sintigrafisi, ASA; asetilsalisilik asit, ACE: angiotensin converting enzim, ARB: angiotensin reseptör blokeri MRA: minereloreseptör antagonisti, KKB: kalsiyum kanal blokeri, YOAK; yeni nesil oral antikoagülan 
Tablo 2. Hastaların yaşam tarzı değişikliklerine uyum ve medikal tedaviye uyum açısından değerlendirilme

\begin{tabular}{|c|c|c|c|c|c|c|c|c|}
\hline \multirow[b]{2}{*}{ Değişkenler } & \multicolumn{4}{|c|}{ Yaşam tarzı değişikliklerine uyum } & \multicolumn{4}{|c|}{ Medikal tedaviye ve kontrole uyum } \\
\hline & $\begin{array}{l}\text { Uyumsuz } \\
(n=84)\end{array}$ & $\begin{array}{l}\text { Intermediate } \\
(n=168)\end{array}$ & $\begin{array}{l}\text { Uyumlu } \\
(n=144)\end{array}$ & $\begin{array}{l}p \\
\text { değeri }\end{array}$ & $\begin{array}{l}\text { Uyumsuz } \\
(n=33)\end{array}$ & $\begin{array}{l}\text { İntermediate } \\
(n=12)\end{array}$ & $\begin{array}{l}\text { Uyumlu } \\
(n=321)\end{array}$ & $\begin{array}{l}p \\
\text { değeri }\end{array}$ \\
\hline Boy, cm & $158,73 \pm 34,25$ & $165,50 \pm 3,80$ & $164,90 \pm 8,04$ & $<0,001^{*}$ & $158,73 \pm 34,25$ & $165,50 \pm 3,80$ & $164,90 \pm 8,04$ & 0,811 \\
\hline Ağırlık, kg & $79,82 \pm 11,14$ & $70,00 \pm 11,89$ & $78,20 \pm 13,27$ & 0,331 & $79,82 \pm 11,14$ & $70,00 \pm 11,89$ & $78,20 \pm 13,27$ & 0,141 \\
\hline $\mathrm{BMI}, \mathrm{kg} / \mathrm{m}^{2}$ & $42,59 \pm 44,46$ & $25,42 \pm 3,38$ & $28,17 \pm 5,61$ & $0,019^{*}$ & $42,59 \pm 44,46$ & $25,42 \pm 3,38$ & $28,17 \pm 5,61$ & $0,026^{*}$ \\
\hline BSA, $\mathrm{m}^{2}$ & $1,87 \pm 0,32$ & $1,79 \pm 0,17$ & $1,85 \pm 0,32$ & $0,044^{*}$ & $1,87 \pm 0,32$ & $1,79 \pm 0,17$ & $1,85 \pm 0,32$ & 0,31 \\
\hline Yaş, yıl & $62,55 \pm 13,63$ & $64,25 \pm 11,73$ & $64,22 \pm 8,50$ & $0,029 *$ & $62,55 \pm 13,63$ & $64,25 \pm 11,73$ & $64,22 \pm 8,50$ & 0,948 \\
\hline \multicolumn{9}{|l|}{ Cinsiyet } \\
\hline Erkek & $54(\% 19,57)$ & $105(\% 38,04)$ & $117(\% 42,39)$ & \multirow{2}{*}{$0,001^{*}$} & $21(\% 8,24)$ & $12(\% 4,71)$ & $222(\% 87,06)$ & \multirow{2}{*}{0,054} \\
\hline Kadin & $29(\% 24,17)$ & $63(\% 52,50)$ & $28(\% 23,34)$ & & $12(\% 10,81)$ & $0(\% 0,00)$ & $99(\% 89,19)$ & \\
\hline \multicolumn{9}{|l|}{ Medeni durum } \\
\hline Bekar & $2(\% 22,22)$ & $4(\% 44,44)$ & $3(\% 33,33)$ & & $2(\% 33,33)$ & $0(\% 0,00)$ & $4(\% 66,67)$ & \\
\hline Dul & $15(\% 27,78)$ & $21(\% 38,89)$ & $18(\% 33,33)$ & \multirow[t]{2}{*}{0,627} & $6(\% 12,50)$ & $3(\% 6,25)$ & $39(\% 81,25)$ & \multirow[t]{2}{*}{$0,048^{*}$} \\
\hline Evli & $66(\% 19,82)$ & $144(\% 43,24)$ & $123(\% 36,94)$ & & $24(\% 7,77)$ & $9(\% 2,91)$ & $276(\% 89,32)$ & \\
\hline \multicolumn{9}{|l|}{ Eğitim durumu } \\
\hline İlkokul & $57(\% 23,75)$ & $117(\% 48,75)$ & $66(\% 27,50)$ & & $24(\% 10,67)$ & $9(\% 4,00)$ & $192(\% 85,33)$ & \\
\hline Lise & $9(\% 13,04)$ & $24(\% 34,78)$ & $36(\% 52,17)$ & & $2(\% 3,51)$ & $2(\% 3,51)$ & $53(\% 92,98)$ & \\
\hline Ortaokul & $15(\% 45,45)$ & $6(\% 18,18)$ & $12(\% 36,36)$ & \multirow[t]{3}{*}{$<0,001^{*}$} & $0(\% 0,00)$ & $0(\% 0,00)$ & $29(\% 100,00)$ & \multirow[t]{3}{*}{0,202} \\
\hline Universite & $2(\% 4,44)$ & $19(\% 42,22)$ & $24(\% 53,33)$ & & $5(\% 12,20)$ & $0(\% 0,00)$ & $36(\% 87,80)$ & \\
\hline Yukseklisans & $0(\% 0,00)$ & $2(\% 33,33)$ & $4(\% 66,67)$ & & $0(\% 0,00)$ & $0(\% 0,00)$ & $9(\% 100,00)$ & \\
\hline \multicolumn{9}{|l|}{ Sosyal güvence } \\
\hline Bagkur & $24(\% 36,36)$ & $30(\% 45,45)$ & $12(\% 18,18)$ & & $5(\% 8,33)$ & $4(\% 6,67)$ & $51(\% 85,00)$ & \\
\hline Emekli sandigi & $18(\% 17,65)$ & $33(\% 32,35)$ & $51(\% 50,00)$ & & $6(\% 6,67)$ & $0(\% 0,00)$ & $84(\% 93,33)$ & \\
\hline Ssk & $39(\% 18,06)$ & $99(\% 45,83)$ & $78(\% 36,11)$ & \multirow[t]{3}{*}{$<0,001^{*}$} & $21(\% 10,14)$ & $9(\% 4,35)$ & $177(\% 85,51)$ & \multirow[t]{3}{*}{0,55} \\
\hline Diger & $2(\% 25,00)$ & $4(\% 50,00)$ & $2(\% 25,00)$ & & $0(\% 0,00)$ & $0(\% 0,00)$ & $6(\% 100,00)$ & \\
\hline Yok & $0(\% 0,00)$ & $3(\% 100,00)$ & $0(\% 0,00)$ & & $0(\% 0,00)$ & $0(\% 0,00)$ & $4(\% 100,00)$ & \\
\hline \multicolumn{9}{|l|}{ Gelir düzeyi } \\
\hline $0-2000$ も & $54(\% 25,71)$ & $96(\% 45,71)$ & $60(\% 28,57)$ & \multirow{3}{*}{$<0,001^{*}$} & $12(\% 6,06)$ & $12(\% 6,06)$ & $174(\% 87,88)$ & \multirow{3}{*}{$0,001^{*}$} \\
\hline $2000-4000 t$ & $27(\% 15,79)$ & $72(\% 42,11)$ & $72(\% 42,11)$ & & $18(\% 11,54)$ & $0(\% 0,00)$ & $138(\% 88,46)$ & \\
\hline $4000 も$ ve üzeri & $0(\% 0,00)$ & $0(\% 0,00)$ & $12(\% 100,00)$ & & $3(\% 33,33)$ & $0(\% 0,00)$ & $6(\% 66,67)$ & \\
\hline HT, var & $48(\% 20,78)$ & $96(\% 41,56)$ & $87(\% 37,66)$ & 0,817 & $9(\% 4,23)$ & $3(\% 1,41)$ & $201(\% 94,37)$ & $<0,001^{*}$ \\
\hline HL, var & $45(\% 20,83)$ & $81(\% 37,50)$ & $90(\% 41,67)$ & $0,04^{*}$ & $15(\% 7,58)$ & $3(\% 1,52)$ & $180(\% 90,91)$ & 0,061 \\
\hline KY, var & $12(\% 16,67)$ & $33(\% 45,83)$ & $27(\% 37,50)$ & 0,569 & $3(\% 4,76)$ & $0(\% 0,00)$ & $60(\% 95,24)$ & 0,105 \\
\hline DM, var & $27(\% 15,25)$ & $87(\% 49,15)$ & $63(\% 35,59)$ & $0,012^{*}$ & $18(\% 11,11)$ & $0(\% 0,00)$ & $144(\% 88,89)$ & $0,004^{*}$ \\
\hline \multicolumn{9}{|l|}{$\begin{array}{l}\text { Diyabet tedavi } \\
\text { rejimi }\end{array}$} \\
\hline İnsulin & $3(\% 5,56)$ & $24(\% 44,44)$ & $27(\% 50,00)$ & \multirow{2}{*}{0,002} & $0(\% 0,00)$ & $0(\% 0,00)$ & $47(\% 100,00)$ & \multirow{2}{*}{0,004} \\
\hline Oad & $24(\% 21,05)$ & $60(\% 52,63)$ & $30(\% 26,32)$ & & $12(\% 11,43)$ & $0(\% 0,00)$ & $93(\% 88,57)$ & \\
\hline \multicolumn{9}{|l|}{ Ek hastalık } \\
\hline Tiroid bzk. & $0(\% 0,00)$ & $9(\% 50,00)$ & $9(\% 50,00)$ & & $3(\% 16,67)$ & $0(\% 0,00)$ & $15(\% 83,33)$ & \\
\hline Kby & $0(\% 0,00)$ & $3(\% 16,67)$ & $15(\% 83,33)$ & & $3(\% 16,67)$ & $0(\% 0,00)$ & $15(\% 83,33)$ & \\
\hline Koah & $6(\% 15,38)$ & $24(\% 61,54)$ & $9(\% 23,08)$ & $<0,001$ & $0(\% 0,00)$ & $2(\% 9,09)$ & $30(\% 90,91)$ & 0,056 \\
\hline Diger & $18(\% 26,09)$ & $27(\% 39,13)$ & $24(\% 34,78)$ & & $9(\% 15,00)$ & $0(\% 0,00)$ & $51(\% 85,00)$ & \\
\hline Yok & $60(\% 23,81)$ & $105(\% 41,67)$ & $87(\% 34,52)$ & & $18(\% 7,59)$ & $9(\% 3,80)$ & $210(\% 88,61)$ & \\
\hline
\end{tabular}




\begin{tabular}{|c|c|c|c|c|c|c|c|c|}
\hline \multicolumn{9}{|l|}{$\begin{array}{l}\text { Alınan müdahale } \\
\text { kararı }\end{array}$} \\
\hline KABG & $24(\% 27,59)$ & $21(\% 24,14)$ & $42(\% 48,28)$ & \multirow{3}{*}{$0,001^{*}$} & $3(\% 3,57)$ & $0(\% 0,00)$ & $81(\% 96,43)$ & \multirow{3}{*}{$0,002^{*}$} \\
\hline Stent & $39(\% 16,67)$ & $114(\% 48,72)$ & $81(\% 34,62)$ & & $27(\% 12,50)$ & $12(\% 5,56)$ & $177(\% 81,94)$ & \\
\hline Yok & $21(\% 28,00)$ & $34(\% 45,33)$ & $20(\% 26,67)$ & & $3(\% 4,55)$ & $0(\% 0,00)$ & $63(\% 95,45)$ & \\
\hline \multicolumn{9}{|l|}{$\begin{array}{l}\text { Girişim yapılma } \\
\text { nedeni }\end{array}$} \\
\hline Usap & $9(\% 17,65)$ & $27(\% 52,94)$ & $15(\% 29,41)$ & \multirow{5}{*}{$0,004^{*}$} & $9(\% 17,65)$ & $0(\% 0,00)$ & $42(\% 82,35)$ & \multirow{5}{*}{$<0,001^{*}$} \\
\hline Nstemi & $12(\% 16,67)$ & $42(\% 58,33)$ & $18(\% 25,00)$ & & $15(\% 22,73)$ & $6(\% 9,09)$ & $45(\% 68,18)$ & \\
\hline Stemi & $27(\% 23,08)$ & $48(\% 41,03)$ & $42(\% 35,90)$ & & $6(\% 5,71)$ & $0(\% 0,00)$ & $99(\% 94,29)$ & \\
\hline $\begin{array}{l}\text { Stabil Angina } \\
\text {-Mps Pozitifligi }\end{array}$ & $24(\% 19,51)$ & $42(\% 34,15)$ & $57(\% 46,34)$ & & $3(\% 2,63)$ & $6(\% 5,26)$ & $105(\% 92,11)$ & \\
\hline Olumcul -Aritmi & $0(\% 0,00)$ & $3(\% 25,00)$ & $9(\% 75,00)$ & & $0(\% 0,00)$ & $0(\% 0,00)$ & $12(\% 100,00)$ & \\
\hline
\end{tabular}

BMI: Vücut kitle indeksi, BSA: Vücut yüzey alanı, HT: Hipertansiyon, HL: Hiperlipidemi, KY: Kalp yetmezliği, DM: Diyabetes mellitus, OAD: Oral antidiyabetik, KBY: Kronik böbrek yetmezliği, KOAH: Kronik obstruktif akciğer hastalığı, KABG: Koroner arter by-pass cerrahisi. *: $p<0,05$

Tablo 3. Yaşam tarzı değişikliklerine uyum üzerine etkili olabilecek faktörler ile ilgili univariate ve multivariate lojistik regresyon analizi

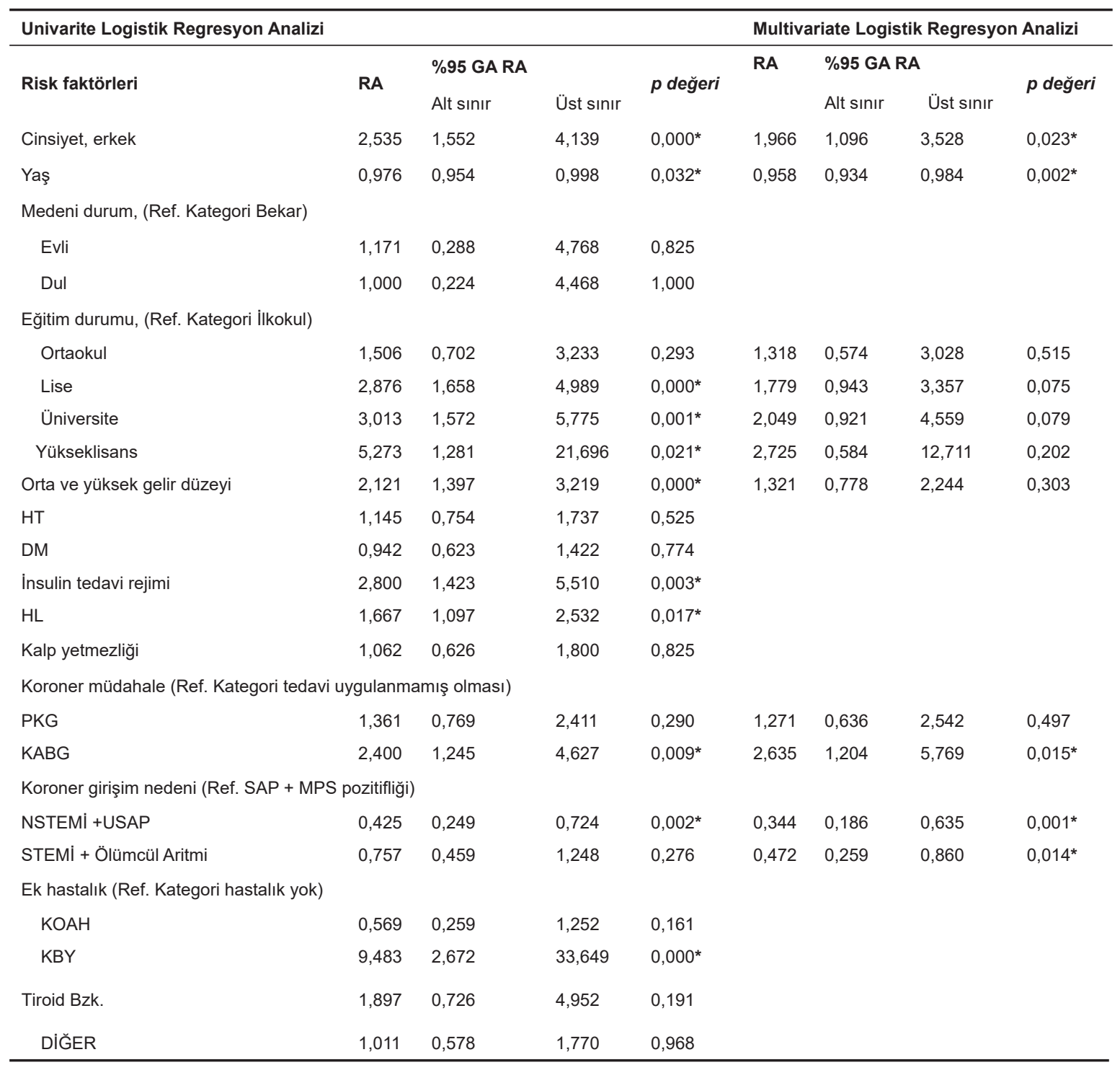

HT; Hipertansiyon, DM; Diyabetes mellitus, HL; Hiperlipidemi, KABG; Koroner arter by-pass cerrahisi, NSTEMI; ST segment elevasyonsuz miyokard enfarktüsü, STEMI; ST segment elevasyonlu miyokard enfarktüsü, USAP; Kararsız angina pektoris, MPS; Miyokard perfüzyon sintigrafisi, KOAH; Kronik obstruktif akciğer hastalığı, KBY; Kronik böbrek yetmezliği

PKG: Perkutan koroner girişim, DIĞER; belirtilmeyen diğer ek hastalıkların toplamı grubunu belirtir RA: risk artışı, GA: güven aralığı bzk: bozukluğu *: $p<0,05$

Not: Orta ve yüksek gelir grubu birleştirilmiş, regresyon analizi düşük gelir grubu referans alınarak yapılmıştır 
stabil angina ve miyokard perfuzyon sintigrafisi pozitifliği nedeniyle KAG yapılanlara kıyasla, NSTEMI/USAP nedeniyle KAG yapılmış olması (RA:0,344, $p=0,001$ ) ve STEMI/ölümcül aritmi nedeniyle KAG yapılmış olması (RA:0,472 $p=0,014)$ YTD'ye tam uyumluluk üzerine negatif etkili saptanmıştır.

\section{Medikal tedaviye tam uyumluluğun değerlendirilmesi}

Tablo 4, MT'ye tam uyumluluk üzerine etkili olabilecek faktörler ile ilgili univariate ve multivariate lojistik regresyon analizini göstermektedir. HT (RA:4,606, p<0,001) ve $\mathrm{HL}$ (RA:1,915, $p=0,045)$ olması MT'ye uyumu arttırırken, perkütan koroner girişim uygulanmasI (RA:0,216 $p=0,013)$, NSTEMI/ USAP nedeniyle KAG yapılması (RA:0,249, $p=0,001) \quad$ MT'ye uyumu azaltmaktadır. Multivariate lojistik regresyon analizine göre HT olması (RA:5,779 $p<0,001)$, STEMI/ölümcül aritmi (RA:3,736, $p=0,029)$ varlı̆̆ı MT'ye uyumu arttırırken, perkütan koroner girişim uygulanması (RA:0,132, $p=0,002)$ MT'ye uyumu azaltmaktadır.

Tablo 4. Medikal tedaviye uyum üzerine etkili olabilecek faktörler ile ilgili univariate ve multivariate lojistik regresyon analizi

\begin{tabular}{|c|c|c|c|c|c|c|c|c|}
\hline \multicolumn{5}{|c|}{ Univarite Logistik Regresyon Analizi } & \multicolumn{4}{|c|}{ Multivariate Logistik Regresyon Analizi } \\
\hline \multirow{2}{*}{ Risk faktörleri } & \multirow{2}{*}{ RA } & \multicolumn{2}{|c|}{$\% 95$ GA RA } & \multirow{2}{*}{ p değeri } & \multirow[t]{2}{*}{ RA } & \multicolumn{2}{|c|}{$\% 95$ GA RA } & \multirow{2}{*}{ p değeri } \\
\hline & & Alt sınır & Üst sınır & & & Alt sınır & Üst sınır & \\
\hline Cinsiyet, erkek & 0,815 & 0,404 & 1,645 & 0,569 & & & & \\
\hline Yaş & 1,014 & 0,981 & 1,049 & 0,401 & & & & \\
\hline \multicolumn{9}{|c|}{ Medeni durum, (Ref. Kategori Bekar) } \\
\hline Evli & 4,182 & 0,999 & 17,512 & 0,050 & & & & \\
\hline Dul & 2,167 & 0,453 & 10,352 & 0,333 & & & & \\
\hline $\begin{array}{l}\text { Orta ve yüksek } \\
\text { gelir düzeyi }\end{array}$ & 0,946 & 0,506 & 1,769 & 0,862 & & & & \\
\hline HT & 4,606 & 2,291 & 9,260 & $0,000^{*}$ & 5,779 & 2,597 & 12,860 & $0,000^{*}$ \\
\hline DM & 1,220 & 0,646 & 2,304 & 0,539 & & & & \\
\hline $\mathrm{HL}$ & 1,915 & 1,014 & 3,616 & $0,045^{*}$ & 0,842 & 0,393 & 1,801 & 0,657 \\
\hline Kalp yetmezliği & 3,218 & 0,965 & 10,733 & 0,057 & & & & \\
\hline \multicolumn{9}{|c|}{ Koroner müdahale (Ref. Kategori tedavi uygulanmamış olması) } \\
\hline PKG & 0,216 & 0,065 & 0,724 & $0,013^{*}$ & 0,132 & 0,036 & 0,487 & $0,002^{*}$ \\
\hline KABG & 1,286 & 0,251 & 6,587 & 0,763 & 0,892 & 0,165 & 4,820 & 0,894 \\
\hline \multicolumn{9}{|c|}{ Koroner girişim nedeni (Ref. SAP + MPS pozitifliği) } \\
\hline NSTEMI + USAP & 0,216 & 0,065 & 0,724 & $0,013^{*}$ & 0,452 & 0,188 & 1,089 & 0,077 \\
\hline $\begin{array}{l}\text { STEMİ + Ölümcül } \\
\text { Aritmi }\end{array}$ & 1,286 & 0,251 & 6,587 & 0,763 & 3,736 & 1,141 & 12,233 & $0,029 *$ \\
\hline \multicolumn{9}{|c|}{ Ek hastalık (Ref. Kategori hastalık yok) } \\
\hline $\mathrm{KOAH}$ & 1,286 & 0,367 & 4,499 & 0,694 & & & & \\
\hline KBY & 0,643 & 0,175 & 2,365 & 0,506 & & & & \\
\hline Tiroid Bzk. & 0,643 & 0,175 & 2,365 & 0,506 & & & & \\
\hline DİĞER & 0,729 & 0,323 & 1,644 & 0,446 & & & & \\
\hline
\end{tabular}

HT; Hipertansiyon, DM; Diyabetes mellitus, HL; Hiperlipidemi, KABG; Koroner arter by-pass cerrahisi, NSTEMI; ST segment elevasyonsuz miyokard enfarktüsü, STEMi; ST segment elevasyonlu miyokard enfarktüsü, USAP; Kararsız angina pektoris, MPS; Miyokard perfüzyon sintigrafisi, KOAH; Kronik obstruktif akciğer hastalığı, KBY; Kronik böbrek yetmezliği, PKG: Perkutan koroner girişim DİĞR; belirtilmeyen diğer ek hastalıkların toplamı grubunu belirtir, RA: risk artışı, GA: güven aralığı bzk: bozukluğu, *: $p<0,05$

Not: Orta ve yüksek gelir grubu birleştirilmiş, regresyon analizi düşük gelir grubu referans alınarak yapılmıştır 


\section{Tartışma}

Çalışmamızda, KAH hastalarında MT'ye uyum YTD'ye uyumdan daha fazla bulunmuştur. Genç yaş gelir düzeyi daha yüksek olan erkekler YTD'ye daha uyumludur. Stent implantasyonu MT'ye uyumu azalttığı saptanırken, KABG yapılması YTD'ye uyumu arttırdığı gözlenmektedir.

Sosyal, psikolojik, çevresel, ekonomik, sağlık sistemi ve bireysel faktörler MT ve YTD'ye uyumu etkilemektedir. Sağlık çalışanları tarafından hastalık bilgisinin yeterli aktarılması, risk faktörlerinin anlatılması ve MT'ye devamlılığı konusunda kritik role sahiptir. Ülkemizde $\mathrm{KAH}$ hastalarında MT ve YTD'ye uyum konusunda yapılan çalışmalar kısıtlı kalmaktadır.

Çalışmamız popülasyonunda MT uyum gösteren hasta sayısı \%81,1 olarak saptanırken YTD tam uyum sağlayan hasta oranı \%36,4'tür. Diğer çalışmalarda bu oran çoğunlukla daha düşük saptansa da [7-9]. Çinde yapılan 3 aylık takip çalışmasında MT ve YTD uyum oranı çalışmamızla benzer saptanmıştır. Bu çalışmada da kalp sağlığı için sağlıklı yaşam tarzı oranı \%15 saptanmış olup başka bir çalışmayla da benzerdir $[10,11]$. Çalışmamız 3. basamak hastaneye başvuran hastalar üzerinde yapıldığı için MT'ye uyum oranı daha yüksek bulunmasına rağmen bizim popülasyonumuz için YTD'ye uyum oranının MT'ye kıyasla düşük olduğu söylenebilir.

Çalışmalarda sekonder korumada cinsiyetin etkisi üzerine çelişkili sonuçlar mevcuttur. Jackevicius ve ark. [8] miyokard enfarktüsü sonrası Kanadalı yaşlı hastalar üzerinde yaptıkları çalışmada, daha genç ve düşük gelirli hastaların MT'ye uyumunun daha az olduğunu saptarken, Lee ve ark. [12] artan yaş ve kadın cinsiyetin MT'ye uyumu azalttığını göstermişlerdir. Çalışmamızda genç yaşerkek hastalar YTD'ye daha fazla uyumlu iken bu etki MT konusunda saptanmamıştır.

Çalışmamızda hastaların \%56,8'i ilkokul mezunu olup bu hastaların \%85,3'ü MT'ye uyum gösterirken sadece \%27,5'u YTD'ye dikkat etmektedir. Üniversite mezunu olan hastaların $\% 87,80$ 'i MT'ye tam uyum gösterirken, aynı eğitim grubunda hastaların sadece \%53'ü YTD'ye uyum sağlamıştır. Gelir düzeyinin orta ve yüksek olması, daha iyi eğitim durumu YTD'ye tam uyumu pozitif yönde etkilerken MT üzerine net etki saptanmamıştır. Çeşitli çalışmalarda medeni durum, eğitim durumu, geliri düzeyi gibi demografik değişenlerin sekonder korumaya uyumda etkili olabileceği gösterilmiştir. Amerika Birleşik Devletleri'ndeki DM hastaları üzerinde yapılan bir çalışmada evli bireyler eşlerinden sosyal destek ve davranış kontrolüalmakta, bu durumun da sekonder korumada uyumu arttırdığı gösterilmiştir [13]. Daha yüksek eğitim düzeyine sahip hastaların sağlıklı değişiklikler yapma ve bunlara daha iyi uyma olasılıklarının daha yüksek olduğu bildirilmiştir [14]. Çalışmalar ayrıca MT'ye uyumu etkileyecek hasta tutumlarını, streslerini ve hastalık anlayışlarını da incelemişlerdir. Molloy ve ark. [15] partner stresinin ve sosyal çevrenin tedaviye uyumu etkilediğini ve yüksek partner stresininmiyokard enfarktüsü sonrası 12. ayda kötü uyumla ilişkili olduğunu göstermişlerdir. Hastaya özgü faktörlerin yanı sıra ayakta tedavi, bakım koordinasyonu ve taburcu ilaç danışmanlığı gibi sağlık sistemine özgü faktörlerin MT'ye uyum ile ilişkili bulunmuştur. Ülkemizde MT'ye daha kolay ulaşılmakta olup demografik ve sosyal değişkenler YTD'yi daha fazla etkilemektedir gibi görünmektedir.

Sigara içme öyküsü olan hasta grubunda hastalık sonrası sigara bırakma oranı \%59 olarak saptanmıştır. Az sayıda hasta $\mathrm{KAH}$ tanısı aldıktan sonra sigaraya tekrar başlamıştır. Sigara birçok hastalık için iyi bilinen bir risk faktörü olup hastalarda bu konudaki bilgi ve duyarlılık düzeyinin daha yüksek olması bu sonuca neden olmuş olabilir. Ek olarak hastaların \%73'ü kalp rahatsızlığı gelişeceğini bilseydi sigarayı önceden bırakacaklarını beyan etmişlerdir. Bu konu sigaranın kalp üzerindeki olumsuz etkileri konusunda daha fazla topluma bilgilendirme yapılması gerektiğini gösterebilir.

HT varlığı MT'ye uyumu arttırırken ve bu etki YTD'ye uyumda mevcut değildir. Ayrıca HT'si olan hastaların \%94,3'ü MT'ye uyum gösterirken bu hastaların yaklaşık üçte biri YTD'ye uyum sağlamışlardır. Diyet ve egzersizin HT kontrolünde önemli etkileri mevcuttur. Hastaların bu etkiler hakkında yeterli bilgi verilmiyor olması ya da MT ile yeterli kontrol sağlanabileceği düşüncesi bu etkiyi yaratıyor olabilir.

Girişim yapılma nedeni hem MT'ye hem de YTD'ye uyumu etkilemektedir. NSTEMI/USAP nedeniyle girişim yapılanlar her ikisine de daha az uyumludur ancak ölümcül aritmi/STEMI 
MT'ye uyumda pozitif etkiliyken YTD'ye uyumu negatif olarak etkilemektedir. Çalışmamızda AKS sonrası MT'ye uyum oranı $\% 53,44$ olarak bulunmuş olup STEMI geçiren hastalarda bu oran \%94,2'dir. Bir meta-analizde akut koroner sendrom sonrası 1 yıl içinde MT'ye uyum \%5486 arasında iken [7] başka bir meta-analiz, 24 ay sonra medyan değerin \%66 olduğunu göstermiştir [16]. Yaklaşık olarak çalışmamızla benzerdir. Bir çalışmada hastaneye yatmanın hayati bir durum olduğu bu da hastalıkların ciddi sonuçları konusunda daha bilinçli kıldığı, belki de tedaviye uyumu artırabileceği düşünülmüş olup bu etkinin hastanede yatış sırasında hemşirelerinden ve doktorlarından aldıkları eğitim, uyumu artırmak için bilgi ve motivasyonla ilgili olduğu söylenmiştir [17]. Çalışmamızda bu durum daha stabil klinik tablo ile seyredebilen NSTEMI/USAP hastalarının yatış esnasında hastalıkları hakkındaki daha az aydınlatılıyor olmasından kaynaklanıyor olabilir. Çalışmamızda ayrıca stent implantasyonunun MT'ye uyumu azalttığı gösterilmiştir. Koroner girişimden sonra MT'yi bırakma nedeni olarak en sık sebep çok fazla ilaç kullanımı $(\% 59,3)$ olarak belirtilmiştir. İkili antiplatelet tedavi süresi hakkında sadece $\% 52,9$ hastaya bilgi verilmiştir. Ülkemizde $\mathrm{KAH}$ hastalarında tedaviye uyumun polifarmasi ve multimorbidite ile ilişkisinin değerlendirilmesi amacıyla yapılan bir çalışmada ilaç kullanım süresinin, günlük ilaç sayısının, hastaneye yatış sayısının, yaşın ve eşlik eden hastalıkların KAH tanılı hastalarda tedavi uyumunu etkilediği görülmüştür. Kullanılan günlük ilaç sayısı azaldıkça tedavi uyumunun azaldığı gözlenmiştir; bu durumun $\mathrm{KAH}$ ile ilgili farkındalığın yetersiz olmasıyla ilişkili olabileceği düşünülmüştür [18]. $\mathrm{KAH}$ hastalarına statin tedavisine uyum konusunda yapılan bir çalışmada yoğun statin tedavisinin öneminin hastalar ve hekimler tarafından tam anlaşılmadığını gösterilmiştir [19]. Polifarmasinin KAH'lı hastalardaki tedavi uyumu üzerine etkileri hakkında daha geniş çok merkezli çalışmalara intiyaç var gibi görünmektedir.

KABG yapılması YTD'ye uyumda MT'den daha etkili görünmektedir. KABG yapılan hastalar cerrahi sonrası fizyoterapi dahil olmak üzere daha fazla klinisyen görüşü alabilmektedir. Bu durum YTD'ye uyumu arttırabilir.

\section{Kısıtlılıklar}

Bu çalışmanın bazı kısıtlılıkları mevcuttur. Birincisi, 3. basamak hastaneye gelen belli bir bölgedeki hastalar üzerinde yapılıyor olması MT'ye uyumda daha iyimser bir sonuca neden olmuş olabilir. İkincisi tek merkez ve tek bir bölgede yapılmış olması ülkemizin diğer bölgeleri için geçerliliği tartışılabilir. Üçüncüsü hastaların sözel beyanları üzerine yapılmış olup doğruluk konusunda şüphe olabilir. Ayrıca bu konuda ülkemize uyarlanmış tam ölçeklendirilmiş bir anket olmaması nedeniyle kendi hazırladığımız anket formu kullanılmıştır.

Sonuç olarak; çalışmamızda, KAH hastalarında MT'ye uyum YTD'ye uyumdan daha fazla bulunmuştur. Genç yaş erkek hastalar YTD'ye daha fazla uyum sağlarken bu etki MT'de saptanmamıştır. Gelir düzeyinin orta ve yüksek olması YTD'ne uyumu pozitif yönde etkilerken MT üzerine etki saptanmamıştır. Girişim yapılma nedeni MT ve YTD'ye uyumu etkilemektedir. NSTEMI/USAP nedeniyle girişim yapılanlar her ikisine de daha az uyumludur ancak ölümcül aritmi/STEMI MT'ye uyumda pozitif etkiliyken YTD'ye uyumu negatif olarak etkilemektedir. Stent implantasyonu MT'ye uyumu azaltmaktadır. KABG yapılması YTD'ye uyumda MT'den daha etkili görünmektedir. Elde edilen bulgular ülkemizdeki $\mathrm{KAH}$ tanısı almış hastaların sekonder koruma konusunda geliştirilmesi gereken konulara ışık tutmakla birlikte, MT ve YTD uyumu etkileyecek sosyal, ekonomik ve psikolojik yönlerden değerlendirecek çok merkezli daha geniş çapta çalışmalara intiyaç vardır.

Çıkar ilişkisi: Yazarlar çıkar ilişkisi olmadığnı beyan eder.

\section{Kaynaklar}

1. Hanna IR, Wenger NK. Secondary prevention of coronary heart disease in elderly patients. Am Fam Physician 2005;71:2289-2296.

2. Han E, Suh DC, Lee SM, Jang S. The impact of medication adherence on health outcomes for chronic metabolic diseases: a retrospective cohort study. Res Social Adm Pharm 2014;10:87-98. https://doi. org/10.1016/j.sapharm.2014.02.001

3. Cutler RL, Fernandez Llimos F, Frommer M, Benrimoj C, Garcia Cardenas V. Economic impact of medication non-adherence by disease groups: a systematic review. BMJ Open 2018;8:e016982. https://doi.org/10.1136/ bmjopen-2017-016982

4. Melloni C, Alexander KP, Ou FS, et al. Predictors of early discontinuation of evidence-based medicine after acute coronary syndrome. Am J Cardiol 2009;104:175181. https://doi.org/10.1016/j.amjcard.2009.03.013 
5. Ho PM, Magid DJ, Shetterly SM, et al. Medication nonadherence is associated with a broad range of adverse outcomes in patients with coronary artery disease. Am Heart J 2008;155:772-779. https://doi. org/10.1016/j.ahj.2007.12.011

6. Catapano AL, Graham I, De Backer G, et al. 2016 ESC/ EAS guidelines for the management of dyslipidaemias. Rev Esp Cardiol (Engl Ed) 2016;74:1234-1318. https:// doi.org/10.1016/j.rec.2017.01.002

7. Chen HY, Saczynski JS, Lapane KL, Kiefe Cl, Goldberg RJ. Adherence to evidence-based secondary prevention pharmacotherapy in patients after an acute coronary syndrome: a systematic review. Heart Lung 2015;44:299-308. https://doi.org/10.1016/j. hrtlng.2015.02.004

8. Jackevicius CA, Li P, Tu JV. Prevalence, predictors, and outcomes of primary nonadherence after acute myocardial infarction. Circulation 2008;117:1028-1036. https://doi.org/10.1161/ CIRCULATIONAHA.107.706820

9. Lee YM, Kim RB, Lee HJ, et al. Relationships among medication adherence, lifestyle modification, and health-related quality of life in patients with acute myocardial infarction: a cross-sectional study. Health Qual Life Outcomes 2018;16:100. https://doi. org/10.1186/s12955-018-0921-z

10. Franklin JM, Krumme AA, Shrank WH, Matlin OS, Brennan TA, Choudhry NK. Predicting adherence trajectory using initial patterns of medication filling. Am J Manag Care 2015;21:537-544.

11. Lu M, Hravnak M, Ma J, et al. Prediction of changes in adherence to secondary prevention among patients with coronary artery disease. Nurs Res 2020;69:199207. https://doi.org/10.1097/NNR.0000000000000433

12. Lee HY, Cooke CE, Robertson TA. Use of secondary prevention drug therapy in patients with acute coronary syndrome after hospital discharge. J Manag Care Pharm 2008;14:271-280. https://doi.org/10.18553/ jmcp.2008.14.3.271

13. August KJ, Sorkin DH. Marital status and gender differences in managing a chronic illness: the function of health-related social control. Soc Sci Med 2010;71:1831-1838. https://doi.org/10.1016/j. socscimed.2010.08.022

14. Margolis R. Educational differences in healthy behavior changes and adherence among middle-aged Americans. J Health Soc Behav 2013;54:353-368. https://doi.org/10.1177/0022146513489312

15. Molloy GJ, Perkins Porras L, Strike PC, Steptoe A. Social networks and partner stress as predictors of adherence to medication, rehabilitation attendance, and quality of life following acute coronary syndrome. Health Psychol 2008;27:52-58. https://doi. org/10.1037/0278-6133.27.1.52
16. Naderi SH, Bestwick JP, Wald DS. Adherence to drugs that prevent cardiovascular disease: meta-analysis on 376,162 patients. Am J Med 2012;125:882-887. https:// doi.org/10.1016/j.amjmed.2011.12.013

17. Hardy SE, Concato J, Gill TM. Stressful life events among community-living older persons. J Gen Intern Med 2002;17:832-838. https://doi.org/10.1046/j.15251497.2002.20105.x

18. Bulut S, Kafadar D, Yakupoğlu E, Okuyan E. Evaluation of the association of medication adherence with polypharmacy and multimorbidity in patients with coronary artery disease. Ankara Med J 2020:777-789. https://doi.org/10.5505/amj.2020.67044

19. Özdemir T, Şahin I, Avcı Ii, et al. Assessment of factors related to statin non-adherence in patients with established coronary artery disease: a singlecenter observational study. Turk Kardiyol Dern Ars 2017;45:723-730. https://doi.org/10.5543/ tkda.2017.89947

Etik kurul onayı: Bu çalışma, Pamukkale Üniversitesi Tıp Fakültesi, Girişimsel Olmayan Klinik Araştırmalar Etik Kurulu'nun 19.11.2019 tarih ve 20 sayılı kararı ile onay alınmıştır.

\section{Yazarların makaleye olan katkıları}

İ.B. çalışmanın ana fikrini ve hipotezini kurgulamış ve makalenin tartışma bölümünü yazmıştır. C.I.S. teoriyi geliştirmiş, gereç ve yöntem bölümünü düzenlemiştir. Sonuçlar kısmındaki verilerin değerlendirmesini sağlamıştır. Ayrıca tüm yazarlar çalışmanın tamamını tartışmış ve son halini onaylamıştır. 